\title{
A Review on The CFD Analysis of Nano Water Fluid On Helically Coiled Double Tube Heat Exchanger
}

\author{
Sunil Kumar \\ M. Tech. Scholar \\ IES College of Technology \\ Bhopal, India \\ sunil.hn.yadav@gmail.com
}

\author{
Ravindra Mohan \\ Professor \\ IES College of Technology \\ Bhopal, India \\ ravindra.mohan09@gmail.com
}

\begin{abstract}
Heat exchanger is an important device which is used in thermal systems in many industrial fields. Nano fluids are recently employed as coolants to improve the efficacy of heat exchangers. Regarding unique characteristics of Nano fluids, research studies in this area have witnessed a remarkable growth. Latest investigations conducted on use of Nano fluids in heat exchangers including those carried out on plate heat exchangers, double pipe heat exchangers, shell and tube heat exchangers, and compact heat exchangers are reviews and summarized. Meanwhile, some very interesting aspects of Nano fluids in combination with heat exchangers are presented. The challenges and prospects for future research are presented in this paper.
\end{abstract}

Keyword: Nanoparticles, Nano fluids, Ag Nano fluids, Heat exchanger.

\section{INTRODUCTION}

New technologies are needed to fulfil the demand of high heat flow processes to enhance heat transfer requirement. Furthermore, there is growing interest in improving the efficiency of existing heat transfer processes. To enhancement heat transfer in the heat exchangers many active and passive techniques are used nowadays. Conventional heat transfer fluids such as water, air, lubricating oil, and ethylene glycol have very poor thermal conductivities compared with metal and metal oxides. Specific properties of conventional fluids can be improved by adding additives in liquid coolants to overcome this limitation. The heat transfer coefficient (heat transfer enhancement) can be improved via the addition of high thermal conductivity solid particles to the liquid coolant. To improve the heat transfer characteristics of conventional fluids thermal conductivity improvement is the key idea. Conventional fluids thermal conductivity enhancement by the suspension of solid particles, such as millimeter or micrometer sized particles, has been well known for more than 100 years. But, larger size particles cause many difficult problems such as agglomeration, clogging, erosion etc. In the flow path of devices. Modern material synthesis technologies and processes overlay the way for synthesize of different nanostructured material which possess quite different thermal, mechanical, electrical and optical properties from the analogous bulk materials. As the confluence of conventional modern nanotechnology and thermal science, for the achievement of enhanced thermal transport characteristics Nano fluids have identified as progressive heat transfer fluids. Argonne national laboratory of United States America first developed the concept of Nano fluids in the year 1995 and discovered its enhanced thermal characteristics. The present review gives a quick overview of important literature presented on the heat exchanger thermal performances and its application working on Nano fluids. 


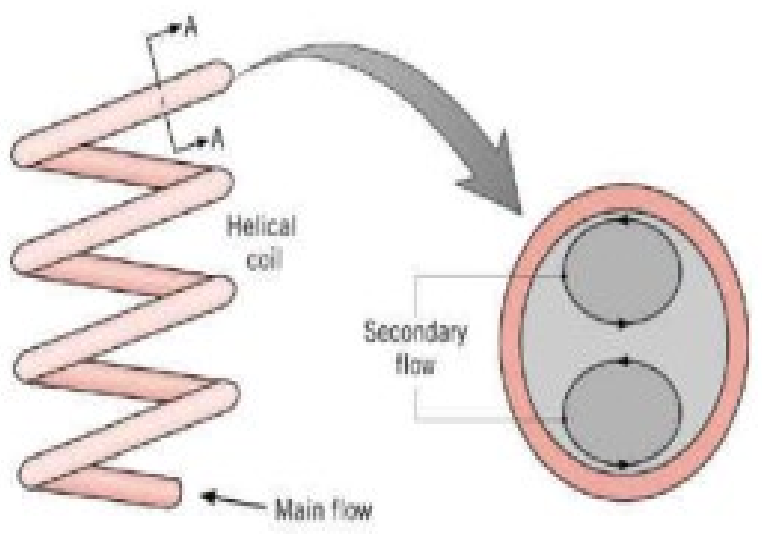

Fig.1. Secondary flow developed due to curvature

\section{LITERATURE REVIEW}

P.C C. Mukesh Kumar et al. [1] In this paper the heat transfer and pressure drop of the double helically coiled heat exchanger handling MWCNT/water Nano fluids have been analyzed by the computational software ANSYS 14.5 version. The computational analysis was carried out under the laminar flow condition in the Dean number range of 1300-2200. The design of new shell and double helically coiled tube heat exchanger was done by using standard designing procedure and 3D modeling was done in Cre-O 2.0 parametric. The Finite Element Analysis software ANSYS Workbench 14.5 was used to perform CFD analysis under the standard working condition. The MWCNT/water Nano fluids at $0.2 \%$, $0.4 \%$, and $0.6 \%$ volume concentrations have been taken for this investigation.

Vimal Kumar et al. [2] In the paper attempts were made to investigate the hydrodynamics and heat transfer characteristics of tube-in-tube helical heat exchanger at the pilot plant scale. The experiments were carried out in counter current mode operation with hot fluid in the tube side and cold fluid in the annulus area. The outer tube was fitted with semicircular plates to support the inner tube and also to provide high turbulence in the annulus region. Overall heat transfer coefficients were calculated and heat transfer coefficients in the inner and outer tube were determined using Wilson plots. A commercial Computational Fluid Dynamics package [FLUENT User's Guide, release 6.0, Fluent Inc., Lebnon, NH, 1994] was used to predict the flow and thermal development in tubein-tube helical heat exchanger.
Miyer j. Valdes et al. [3] this article is a review of the most important studies recently published in this field. It presents the geometries that provide single and double passive enhancements and some of the correlations that are applied to heat exchangers with double passive enhancement. In brief, this work constitutes a thorough review of the results of numerical and/or experimental research - as well as other reviews - in the field of heat exchangers in which the transfer phenomenon has been improved by means of passive techniques.

Ruchal G. Humbare et al. [4] The heat exchangers most widely used are shell and tube heat exchangers which are larger in size and offer lesser heat transfer rate. Also, in shell and tube heat exchanger dead zone is produced which further reduces heat transfer rate and in order to improve heat transfer rate some active techniques are required. Helical heat exchanger is more compact, offer better heat transfer rates and heat transfer rate can be further improved by passive techniques. Its shape offers advantages such as more fluid contact, elimination of dead zones, and secondary turbulence. An experimental test rig was developed for evaluation of tube-in-tube helical coil heat exchanger. This paper deals with parametric analysis and its effect on performance of tubein-tube helical coil heat exchanger.

\section{COMPUTATIONAL FLUID DYNAMICS}

Computational fluid dynamics (CFD) is the use of applied mathematics, physics and computational software to visualize how a gas or liquid flows -- as well as how the gas or liquid affects objects as it flows past. Computational fluid dynamics is based on the NavierStokes equations. These equations describe how the velocity, pressure, temperature, and density of a moving fluid are related.

Computational fluid dynamics has been around since the early 20th century and many people are familiar with it as a tool for analyzing air flow around cars and aircraft. As the cooling infrastructure of server rooms has increased in complexity, CFD has also become a useful tool in the data center for analyzing thermal properties and modeling air flow. CFD software requires information about the size, content and layout of the data center. It uses this information to create a 3D mathematical model on a grid that can be rotated and viewed from different angles. CFD modeling can help an administrator identify hot spots and learn where cold air is being wasted or air is mixing. 


\section{APPLICATIONS OF NANO FLUID}

Nano fluid can be used to cool Automobile Engine, Electronic component and Welding equipment and cool high heat flux device such as high power microwave tube and high power laser diode array. Nano fluid could flow through the tiny passage of equipment to improve the efficiency. Nano fluids that include; engine cooling, engine transmission oil, boiler exhaust flue gas recovery, cooling of electronic circuit, nuclear cooling system, solar water heating, refrigeration, defense and space application, thermal storage, biomedical application, drilling and lubrication.

\section{CONCLUSION}

By studying the application of Nano fluid in turbulent and laminar flows, it was found that thermal conductivity of Nano fluids increases by adding nanoparticles into the base fluid. In general, the effects of nanoparticles on the heat transfer coefficient of homogeneous Nano fluids are insignificant compared to the effects of thermos-physical properties of nanoparticles in the flow. Numerical studies of Nano fluids within the heat exchangers are modeled in both single-phase and two phase models. A single-phase model is considered without any slip between nanoparticles and fluids. However, in two-phase model, the particle slip and particle Brownian motion is considered. As literature shown that use of Nano fluids in heat exchangers enhances its performance characteristics so it is very productive to use Nano fluid instead of conventional fluid.

\section{REFERENCES}

[1] P.C C. Mukesh Kumar, M. Chandrasekar "CFD analysis on heat and flow characteristics of double helically coiled tube heat exchanger handling MWCNT/water nanofluids" DOI: 10.1016/j.heliyon. 2019. E02030.

[2] Vimal Kumar, Supreet Saini "Pressure drop and heat transfer study in tube helical heat exchanger" 61(13):4403-4416 · July 2006.

[3] Miyer j. Valdes, Juan Ardila "Heat exchangers with double passive enhancement” DOI: 10.12988/ces.2018.87321.

[4] Ruchal G. Humbare, Suraj R. Gurav "Analysis of Heat Transfer Enhancement in Tube-in-tube Helical Coil Heat Exchangers" ISSN: 2249 - 8958, Volume-5 Issue-1, October 2015.

[5] B. S. V. S. R. Krishna, "Prediction of Pressure Drop in Helical Coil with Single Phase Flow of Non-Newtonian Fluid", International Journal of Applied Research in Mechanical Engineering, Volume2, Issue-1, 2012.

[6] Hui Zhu, Hanqing Wang, Guangxiao Kou, "Experimental Study on the Heat Transfer Enchancement by Dean Vortices in Spiral Tubes", International Journal of Energy and Environment, Volume 3, Issue no: Special 1, March 2014.
[7] J. S. Jayakumar, Helically Coiled Heat Exchanger, Heat Exchanger - Basics Design Applications, Dr. Jovan Mitrovic(Ed.), March 2012.

[8] M. Kannan, S. Ramu, S. Santhanakrishnan, G. Arunkumar, Vivek M., "Experimental and Analytical comparison of Heat Transfer in Double Pipe Heat Exchanger", Internal Journal of Mechanical Engineering Applications Research, Volume 3, Issue 3, July 2012. 